\title{
The Promise of Internationally Collaborative Research for Studying Occupation: The Example of the Older Women's Food Preparation Study
}

\author{
Clare Hocking, Doris Pierce, Anne Shordike, Valerie Wright-St. Clair, \\ Wannipa Bunrayong, Soisuda Vittayakorn, Phuanjai Rattakorn
}

key words: AQ1

\begin{abstract}
Growing awareness of the Western perspectives underpinning occupational science and occupational therapy's values, theories, and evaluation tools has given rise to questions about culturally relevant knowledge and practice with non-Western populations. To make sense of attempts to develop cross-cultural knowledge taking place within the profession and discipline, the authors review epistemological perspectives and methodological advances in anthropology and psychology. Thus informed, they both summarize and critique constructivist and positivist approaches to knowledge development and practice that cross or resist the crossing of cultures. The authors outline a multicultural collaborative research method that supports extending and refining the profession's knowledge in a way that both honors local perspectives and reveals concepts that cross cultures. Insights from a study that explored the meaning of food preparation to older Thai, American, and New Zealand women provide illustrative examples.
\end{abstract}

$\mathrm{T}$ There is a growing awareness among occupational scientists and therapists that current disciplinary and professional knowledge is predominantly based on Western understandings of people, their occupations, and the interventions that may best serve them. Questions about culturally relevant practices are surfacing around the globe (Iwama, 2003). This article proposes one way in which the discipline and the profession may benefit from honoring cross-cultural understandings of occupation, beginning with a review of the ways other disciplines have managed the challenge of developing and transporting knowledge across international borders. In particular, it discusses how research in established disciplines, such as anthropology and psychology, has extended across cultures and how studies have contributed to a broadening of conceptualizations of central theories and practices in ways that enhance their fit with people of diverse origins.

Underlying and shaping the methods and applications of these disciplines are their epistemological stances, or assumed ways of knowing. More positivist approaches assume a singular reality that can be rigorously assessed through objective scientific methods to generate knowledge that can be safely transferred between cultures. More constructivist views see reality as subjective, perceived within a cultural frame that is not transferable, and best assessed through methods that require and empower the perspectives of individuals immersed in that culture. Pike (1967) described

Clare Hocking, XX, is Associate Professor, and Valerie Wright-St. Clair, XX, is Senior Lecturer, School of Occupational Therapy, Auckland University of Technology, Auckland, New Zealand. Doris Pierce, XX, is Endowed Chair, and Anne Shordike, XX, is Associate Professor, Eastern Kentucky University, Richmond, Kentucky. Wannipa Bunrayong, XX, is Associate Professor, Soisuda Vittayakorn, XX, is Associate Professor, and Phuanjai Rattakorn, XX, is Assistant Professor, School of Occupational Therapy, Chiang Mai University, Chiang Mai, Thailand.

Address correspondence to Clare Hocking at clare.hocking@aut.ac.nz.

This manuscript was accepted under the editorship of Helene J. Polatajko, PhD, OT(C), OT Reg. (Ont.), FCAOT. 
these differing perspectives as the etic view (from phonetics), which uses an external scientific explanation of phenomena and most often a positivist epistemology, and the emic view (from phoneme), which emphasizes individual meanings of those experiencing the phenomenon and most often uses a constructivist epistemology. Adherents to emic versus etic perspectives are often passionate as to the correctness of their approach, but tend not to discuss the epistemologies underlying their proposals or their critiques of other approaches. Of course, neither philosophy is right or wrong. They simply show disciplinary differences in epistemology, and thus in what is considered to be rigorous or trustworthy.

In occupational therapy, researchers exhibit a wide variety of backgrounds that result in differences in epistemologies, methods, and opinions on the transferability of theories and interventions across cultures. Acting on the assumption that it is possible to bridge these epistemological and methodological divides, the authors outline the research method developed for an international study of older women's food preparation occupations in Kentucky, New Zealand, and Thailand. A derived etic approach (Berry, 1989) was used, thus striking a methodological balance between subjective/emic and synthesized/etic perspectives. Local research teams collaboratively analyzed themes, crossing the data of all of the participating regions and enabling limited conclusions across sites to be reached.

This approach holds promise for occupational therapy and occupational science by assisting understanding of the commonalities that may exist despite an occupation taking different forms in different cultures, contributing to the customization of interventions for clients across the regions studied, and refining and testing theoretical concepts from a multi-cultural perspective.

\section{Historical Overview of Research Crossing Cultures in Anthropology and Psychology}

To inform occupational science and therapy about the challenges of research and practice across cultures, it is useful to consider how long-standing disciplines have addressed such issues over their historical development. Although cross-cultural studies are also used in sociology, evolutionary biology, political science, and other disciplines, we review the history of the two disciplines most involved in cross-cultural research: anthropology and psychology. Research that draws on multiple cultures or transports methods and concepts between cultures is interpreted and applied in different ways in differ- ent disciplines. Uncovering the subtle philosophical and methodological differences in research across cultures within two such established disciplines can inform consideration of similar challenges and tensions in occupational science and therapy.

\section{Anthropology}

In the late 1800s, research that crossed cultures formed the basis of the field of anthropology. In essence, this involved a researcher from a Western culture attempting to understand and describe another culture through immersion in the field and rigorous observations of the people and their practices over time. Enormous effort has gone into the refinement of this endeavor. In the 1930s, at the Institute of Human Relations at Yale, the Cross-Cultural Survey was established to index ethnographies from many countries according to a standard Outline of Cultural Materials (Ember \& Ember, 1998). Following the same collection model, the Human Relations Area Files were established and continue to add new cases every year. Additionally, the Ethnographic Atlas was initiated by Ethology in 1962 and now has more than 1,200 cases, and the Standard Ethnographic Sample, initiated in 1973 using strict inclusion criteria, has ethnographic entries from 285 societies (Divale \& Seda, 2001; Gelfand, Raver, \& Ehrhart, 2002). These anthropological collections provide data through which comparisons of cultural practices can be made through archival work.

Although systematic cross-cultural research continues in anthropology, multi-cultural comparative approaches have declined as a primary method of the discipline. The question of how another culture can be rigorously examined through the eyes of an immersed outsider has led to many methodological refinements and debates in this field. Furthermore, the fieldwork method, which requires extensive, year-round (and often repeated) engagement with the people and cultural traditions of a specific group, is now considered a poor match to research efforts by a single researcher across multiple cultures (Ember \& Ember, 1998). Currently, anthropology still sends researchers to study other cultures but such research is generally confined to a single culture.

\section{Psychology}

Although the early German roots of psychology were phenomenological, experimental methods began to gain popularity in the 1950s. In the United States and Europe, behaviorism flourished under the broadening acceptance of empirical, positivist methods, as did cross-cultural research. Perhaps the best-known comparative work in psychology is John 
and Beatrice Whiting's Six Cultures Study, completed in 1962, which described children's behavior in different parts of the world (Ember \& Ember, 1998). The researchers used a single evaluative tool to measure and interpret behavior, assuming that culturally diverse behaviors could be objectively measured and compared from an outsider's perspective.

Cognitive psychology, especially Piagetian approaches to child development, gained popularity in the 1960s and continues to be an important sub-discipline. A wide variety of developmental scales and assessments were developed, many of which were directly translated into other languages for use in comparative research. Again, this empirical approach to evaluating cognition was founded on the assumption that psychological constructs could be objectively measured despite differing cultural contexts. In contrast to the developments in Western psychology at that time, Russian psychology was using a cultural practices perspective, developing cultural-historical activity theories, and was not attempting comparisons across cultures. Vygotsky's Zone of Proximal Development, which describes how a child's development is shaped by his or her immediate social context, is a prominent example of the Russian psychology of this period. Vygotsky's work was later widely adopted in the Western world.

Within the contemporary field of psychology, multiple sub-fields are evident, each holding different understandings of cross-culturally relevant research methods and the application of research findings. The sub-fields reviewed here are cross-cultural psychology, cultural psychology, and indigenous psychology.

Currently, cross-cultural research is in high demand within psychology because the field offers its concepts for application within health care systems, schools, and community planning efforts around the world (Lyons \& Chryssochoou, 2000). This branch of psychology uses quantitative, experimental research methods, and primarily employs the administration of psychometric instruments developed in the United States and translated for use in other cultures. This approach to research is founded on the premise that human psychological processes are common across cultures. In response to criticisms that such studies are subject to a high degree of interpretation error, methods for refining instruments through careful translation, back-translation, and other strategies have been developed (Corless, Nicholas, \& Nokes, 2001; Hines, 1993; McArthur, Anguiano, \& Nocetti, 2001; Michaud, Blum, \& Slap, 2001; Teresi \& Holmes, 2001; van de Vijver, 2001). However, the underlying premise that psychological processes remain constant across cultures is unchanged.
Cultural psychology is phenomenological. It emphasizes individual differences in development, the contextualization of cultural practices, and personal narratives (Berry, Poortinga, Segall, \& Dasen, 2002; Kral, Burkhardt, \& Kidd, 2002; van de Vijver \& Poortinga, 2002). Cultural psychology does not compare across cultures because the meaning of the behaviors examined is seen to be located completely within the culture, although the researcher may be located outside or inside the culture of interest. Concern for interpretive, ecological, and theoretical validity is paramount. The researcher-participant relationship is carefully considered and participatory research is valued.

Indigenous psychology arose as a reaction to Euro-American psychology's lack of attention to issues important to indigenous peoples around the world (Berry et al., 2002; Gibbs, 2001). In this approach, each culture is encouraged to develop its own psychology based on its own culture and values. Methods of indigenous psychology emphasize culturally appropriate relationships and data collection methods and privilege indigenous knowledge rights. The transfer of concepts between indigenous psychology studies is accepted as difficult. Nonetheless, indigenous psychology researchers may not be members of the culture being studied, so the risk of inaccurate interpretation of data still exists.

\section{The Underlying Epistemological Question: Can Knowledge Be Generated and Examined Across Cultures?}

This overview of anthropological and psychological research that crosses cultures or critiques the crossing of cultures demonstrates that different fields and sub-fields come to different conclusions regarding whether cross-cultural research is methodologically possible, appropriate, and trustworthy. The foundations of these differences are basic epistemological stances that shape methods, guide research questions, and limit or support cross-cultural research in each field.

The basic question of epistemology is "How do we know?" Depending on the answer, cross-cultural research might be entirely possible or implausible. Positivists hold that reality is out there and can be discovered and understood, which supports the idea that concepts developed in one place will hold true in another and allows comparison between cultures. Post-positivists agree that reality is out there and inquiry can provide an imperfect knowledge of reality. This perspective suggests that people and experiences can be compared to some degree. On the 
other hand, constructivists view reality as relative, socially constructed, and only able to be interpreted by those within the culture. Comparing findings across cultures is not usually used in constructivist approaches and can only properly proceed once issues of equivalence of importance, meaning, and function have been addressed.

\section{Can We Research and Apply Occupation Across Cultures?}

Faced with such cross-disciplinary variations of epistemologies and methods with regard to research that crosses cultural boundaries, it is not surprising that occupational science and therapy are now questioning whether understandings and applications of human occupation can appropriately cross cultures. Occupational science and therapy researchers bring a mixture of disciplinary backgrounds that assume differing epistemological and methodological stances and thus are bound to disagree on these points. Discussion and clarification is needed, but the issues are complex. In the discussion that follows, some of the approaches used to date in occupational science and therapy research are reviewed and critiqued in light of their epistemological foundations. Following that, the methods developed to study food preparation by older women in three countries are described as an example of how a derived etic method can be used to compare across cultures in a way that honors the local emic view while seeking broader etic concepts that may be shared within similar occupations and across cultures.

\section{The Constructivist Critique}

Similar to cross-cultural American psychology, early occupational therapy approaches developed in the United States and Britain were simply transported to non-Western cultures. Thus, clients in Uganda and Israel were taught to operate floor looms, even though imported thread supplies were uncertain and local weavers employed different technologies and aesthetics (Levy, 1962; Robertson, 1960). Similarly, when Indian clients declined leatherwork because it contravened religious beliefs and the caste system, they were described as being unnecessarily "fussy" (Oza, 1962, p. 45). This denial of local cultural values and the therapeutic potential of local occupations assumed a universality of Western concepts that was based in a positivist epistemology.

Similar concerns have been raised about applying theories developed in the West to people in other contexts and come in several guises. One is to directly challenge whether ideas believed to be "applicable to all ages, cultures, and persons" (Fidler, 1996, p. 140) are in fact "holistic and universal" (Hocking \& Whiteford, 1997, p. 154). Another approach is to critically appraise key concepts of a model and the relationships between concepts in relation to local perspectives.

For example, Haglund and Kjellberg (1999) analyzed Kielhofner's Model of Human Occupation to determine whether it was consistent with values and beliefs underpinning practice in Sweden and how well it aligned with societal values and regulations. A key finding was that Swedish health policies emphasize societal responsibility "to provide the same opportunities for all people, thus preventing a person with a disability from becoming a person with a handicap" (Haglund \& Kjellberg, 1999, p. 107). Accordingly, Swedish occupational therapists routinely evaluate each client's environmental conditions before assessing his or her occupational status and focus on changing the environment in ways that will allow clients to achieve their goals. Haglund and Kjellberg (1999) found the Model of Human Occupation deficient in supporting practice in their context because it underrepresented the role the environment plays in the development of occupational behavior and did not sufficiently explicate "the dialectical interaction between the environment and the individual" (p. 107).

Heightened awareness of cross-cultural issues is also evident in a critical review of values identified as underpinning occupational therapy, which argued that although the values were presented as universally applicable, they are actually grounded in Western perspectives (Hocking \& Whiteford, 1995). Equality and freedom, for example, were conceptualized in terms of individual rights, opportunities, and choices, which overlooks the legitimacy of collectively determined goals and prioritizing the common good over individual advancement. Along with concerns about the theoretical and methodological appropriateness of occupational therapy across cultures, there has been ongoing concern that occupational therapists are culturally competent (Bonder, 2004; Fitzgerald, 2004; Whiteford \& Wilcock, 2000) and informed about cultural differences in occupation (Odawara, 2005).

Central to each of the critical viewpoints described above is recognition that occupational therapy and occupational science are based on Western assumptions that may have a poor fit with people of other backgrounds. That is because both practice and science continue to be influenced by Western scientific tradition, within which the proper way of uncovering truth has traditionally been positivistic, rational, and implemented within human sciences that emphasize individualism, agency, action, and 
the celebration of the self. In this regard, occupational therapy (and most other health professions) is subject to critique by indigenous populations. They assert that practice approaches that are not guided by indigenous philosophies and paradigms fail to address the needs and aspirations of those peoples and often fail to take into account the health disparities between different population groups (Ratima \& Ratima, 2005).

Informed by these perspectives, several critiques of occupational therapy knowledge and practice that are based in a constructivist epistemology have been launched (Hocking \& Whiteford, 1995; Iwama, 2003; Whiteford, Townsend, \& Hocking, 2000). One strategy employed to critique the utility of Western models in other contexts is to identify the culturally specific concepts embedded within them. For instance, Western assumptions underpinning the Model of Human Occupation include activism, a future orientation, individual autonomy, and independence (Hocking, 1999). These assumptions are apparent in the model's view of people, its therapeutic propositions, and its assessment and intervention processes, yet may be incompatible with acceptance of one's circumstances, interdependence, and orientation to the past, which underpin Eastern cultures (Parry, 1984; Yang, Shek, Tsunaka, \& Lim, 2006).

A second strategy has been to identify potential outcomes of uncritically superimposing theory within different cultural contexts. For example, Iwama (2003) argued that philosophical disparities rob the major models of the West "of their profound meanings and potencies" (p. 587) to inform practice in Japan. Stripped of their essential meaning, such theories are reduced to recipe-like approaches. Iwama argued that as a result Japanese occupational therapists risk providing therapy that is:

out of synch with local value patterns and needs [that] may actually prove to be a disservice to our clients. . . . At worst, occupational therapy could be morally and ethically wrong as occupational therapists end up being unwitting agents of oppression, colonizing cultures with ideologies that have dubious meaning and run counter to a given culture's core values. (p. 587)

One response to such concerns is to develop theories that boldly declare their cultural specificity such as the Kawa River Model, which espouses Japanese perspectives of health and its relationship to human action (Iwama, 2005). Similarly, some researchers have opted to develop evaluation tools from scratch because they recognize just how complex translating evaluation tools to other cultures can be and suspect that "explicitly or implicitly" foreign assessments "contain different values and life habit constructs" (Pan, Chern, Chung, \& Lai, 2001, p. 169). Watson and Swartz (2004) proposed that the cultural uniqueness of the various settings in which occupational therapy is practiced mean that the profession's "assumptions, values, and beliefs [must be] adjusted in order to match cultural beliefs" (p. 151). In short, the "collective cultural practices or 'doing' of occupational therapy should be diversified across the globe" (Watson \& Swartz, 2004, p. 151), and initial efforts in this direction have been reported (McGarrigle \& Nelson, 2006; Watson \& Swartz, 2004).

These critiques of the application of Western occupational therapy theory and practices in non-Western cultures demonstrate the underlying assumptions of constructivism - that meaning is local and culturally shaped and is not appropriately transferred to interpret or affect other cultures. The constructivist approach values the emic view that is rooted in the subjective perspective of the individuals being studied. However, the limitation of a constructivist approach is that it assumes that commonalities do not necessarily exist between human cultures. Methodologically, this could prevent comparisons across cultures that seek to discover or describe common patterns or therapeutic applications of occupation that may or may not exist. It also requires each cultural group of occupational therapists and researchers to undertake the formidable task of developing an entire body of local theories, assessments, and interventions.

\section{The Positivist Response}

Occupational therapists' growing awareness of the problems associated with imported knowledge and practices is perhaps most apparent in literature describing the cross-cultural use of evaluation tools. Acknowledging the complexities, some researchers have employed the strategies of cross-cultural psychology, including careful translation processes, verification by back translation, and studies to reestablish reliability and other psychometric properties within new cultures, such as in Chan, Ray, and Trudeau's (2001) translation of the Allen Cognitive Level Screen into Cantonese.

Other researchers have found that rigorous translation processes are not sufficient. Corresponding words and phrases may not exist and the same behavior might serve a different purpose and be perceived differently in culturally divergent contexts. For example, responding to loud sounds by holding your hands over your ears might indicate sensory defensiveness in American children, but be a sensible protective response in Israeli children growing up amidst warning sirens (Neuman, Greenberg, Labo- 
vitz, \& Suzuki, 2004). Accordingly, establishing exact linguistic equivalency was recognized as unrealistic (Neuman et al., 2004) and further study showed that cut off scores established in the United States might result in incorrect classification of children in Israel (Neuman, 2006).

Similarly, Hwang, Nochajski, Linn, and Wu (2004) realized that some items in the School Function Assessment were culturally inappropriate to Taiwan and some culturally appropriate behaviors were not represented. They worked with the test developer to effect a "cultural adaptation" (Hwang et al., 2004, p. 26) that involved identifying items that are not applicable, unsuitable because of differing cultural connotations, performed differently (e.g., using chopsticks rather than a fork), or routinely emphasized in the new context but not the original context. Having modified the test items and protocol accordingly, they advised "caution in the use of the two versions for comparative cross-cultural research" (Hwang et al., 2004, p. 38).

Although adaptations of method described here contribute to more sensitive approaches to research across cultures, the epistemological assumption of positivism (that there is a similar reality underlying occupation in all of these cultures) remains in place. The positivist stance uses an etic approach, which values systematic and scientific explanations developed through rigorous and carefully considered methods. The question remains in regard to how well findings within more positivist methods transcend the barriers of cross-cultural understanding to describe commonalities and differences in cultural groups in terms of occupation and its therapeutic applications. Yet, the positivist stance may support and enable the effort to look at occupation across cultures more effectively than does the constructivist.

\section{The Older Women's Food Preparation Study}

\section{Focusing on the Epistemological Challenge: A Collaborative Derived Etic Method}

Occupational science and therapy have reached the point in their maturation that, as in other disciplines, they must consider their underlying epistemological stance. Too often in the literature of the field, arguments located in completely different epistemologies are posed as criticisms of each other without acknowledging the underlying assumptions that place them at odds. The critiques seem to pass each other without connecting. They simply compete, not resulting in discovered resolutions to research issues. Given the preceding critiques of current approaches to research that crosses cultures, there are perhaps three choices: (1) the constructiv- ist recommendation to develop multiple separate sciences that support practices within specific cultures; (2) the use of post-positivist strategies to improve the imperfect transfer of Western approaches to non-Western peoples; or (3) engagement of these epistemological challenges by developing rigorous methods that can look across cultures while honoring local perspectives. It is this last choice that we have pursued by using a derived etic method.

In our view, collaborative research that crosses cultures has the greatest potential to move both the discipline and the profession from its current occupational understandings and toolkit to those that will emerge as effective across cultural diversity. For occupational therapy and its science to develop core concepts, theories, and practices that are strongly explanatory and coherent, it is necessary that concepts (and later practices) be grounded and tested in multiple cultures. Fulfilling the profession's promise of improving human well-being will require "an expanded understanding of occupation" (Whiteford et al., 2000, p. 62), "culturally relevant practices informed by epistemologies that are truly inclusive, sensitively particular, and meaningful to our clients" (Iwama, 2003, p. 587), and an "interdependent" (Blanche \& Henny-Kohler, 2000, p. 109) style of exchange and collaboration between researchers and practitioners of different cultures.

In the older women's food preparation study, we sought to address this epistemological challenge to occupational science and therapy research through the collaborative derived etic method (Berry, 1989; Berry et al., 2002; Gelfand et al., 2002; Lyons \& Chryssochoou, 2000; Skevington, 2002). This method combines the constructivist and positivist perspectives by striking a balance between strong representations of the local, subjective, and emic perspectives of the women of three regions and the etic, synthesized constructs that were found across the three cultural groups.

In contrast to an etic method, whereby researchers interpret the subjective world from their own perspective, culturally located researchers using the derived etic method stay within their emic perspective to draw out local understandings. This emic aspect of the method is not new to qualitative researchers, although it is unique in requiring that the researchers interpreting local data be of that culture. A distinctly new horizon of understanding is gained, however, when the teams located within each culture collaboratively compare their findings, creating "derived etics," or core explanatory themes that cross cultures. The derived etic method does not seek to discover universals that transcend the cultural groups studied, but rather seeks to comparatively 
describe aspects of the phenomenon of interest commonly held by all participants across those cultures to be important in their understandings of the phenomenon that is the focus of the study.

The following section briefly describes how these methods unfolded and were implemented. For the derived etic method (Berry, 1989) to bridge between the local, constructed, and culturally unique perspectives expressed by participants and still derive etic syntheses that enable comparisons across the three regional groups, several strategies were used: (1) three teams of native researchers working primarily with the data of their own cultures; (2) intensive and careful collaborative development of understandings across the larger research group (the research collaborative including all three cultures); and (3) an analysis sequence that repeatedly moves from grounding in the original, culturally situated data to themes identified as key to the synthesis of constructs across the data of all groups.

\section{History and Purpose of the Collaboration}

The older women's food preparation study was initiated in 1999 by lecturers at the Schools of Occupational Therapy at the Auckland University of Technology in New Zealand and Chiang Mai University in Thailand. They were joined in 2001 by academics from Eastern Kentucky University in the United States. Data analysis was completed in November 2005. The specific topic of the study, the meaning of food preparation, was based in a desire to understand more about occupations commonly employed in therapy.

Older women were identified as participants because of their over-representation within aging populations internationally and our understanding that occupational therapists will be required to develop services relevant to the needs of this age group. The food preparation occupations selected for study were those of important annual rituals in the hope of enhancing our insights through the heightened meanings inherent in the older women's preparing and offering of foods for such valued occasions. Thus, our question became: What are the meanings and experiences in older women of preparing and offering food at Christmas and Songkran (Thai New Year)?

\section{Collaborative Design and Implementation of the Study}

The study design was initially developed by the New Zealand and Thai researchers, who met for a week in Chiang Mai to plan a focus group protocol and semi-structured interview that would work well in both countries (Hocking, Wright-St. Clair, \& Bunrayong, 2002; Wright-St. Clair, Bunrayong, Vittayakorn, Rattakorn, \& Hocking, 2004). At this time, the team intended to produce separate, culturally specific descriptions of the occupations in New Zealand and Thailand. The meeting coincided with Songkran to allow the New Zealand team to gain an appreciation of the festival itself and the women's experience of planning, gathering, cooking, offering, and sharing Songkran foods. Not long after this planning visit, the U.S. team offered to collect data on Christmas food-centered occupations of older women of rural, eastern Kentucky.

Data were collected in the same way in each country, with the exception of asking about Songkran or Christmas foods as appropriate and using differing cultural norms for older age (65 years and older in New Zealand and the United States, 60 years and older in Thailand). Only older women still involved with their families' annual celebrations participated. In each country, there were three focus groups with approximately eight participants in each group and data gathering was completed from late 2000 to early 2001. All nine interviews were fully transcribed. Following consultation, English was chosen as the common language to access the findings. The Thai focus group data were first translated from the northern Thai dialect (used by Thai participants) into government Thai and then into English. When interpreting findings, the Thai researchers continually re-grounded in the original transcripts to ensure meanings were not distorted by the translation.

The researchers analyzed findings within their culturally based teams and, later in the process, independently published their findings (Hocking et al., 2002; Rattakorn, Vittayakorn, Bunrayong, Hocking, \& Wright-St. Clair, 2003; Shordike \& Pierce, 2005; Wright-St. Clair et al., 2004). Mutual understanding of initial findings from New Zealand and Thailand was assisted by a week-long meeting in Auckland in 2001, during which members of the New Zealand and Thai teams worked to make transparent to the other their subjective, or emic, perspective of what participants were saying and what that meant. This process was similar to the reflexive processes in which all qualitative researchers engage to make their assumptions and personal stances evident, but focused on attempting to transmit understanding across cultural differences within the research collaborative. It was a complex process that required in-depth engagement over time and close reference to the data. It also sensitized the team to the possibilities for collaboratively developed understandings of the data. 


\section{Initiating Comparisons}

Members of the three research teams met at the 2002 World Federation of Occupational Therapists Congress to present their separate findings. The potential to embark on internationally comparative work was evident, if we could find the methods. The U.S. team strongly advocated the potential value to occupational science of such methods and findings. We required methods that preserved the perspectives of the different cultural groups, supported rigorous comparisons, and were not so unwieldy as to require decades for completion. Initially, the full team's conceptualization of the comparative analysis process was of a collaborative development of a coding scheme to enable management of the large amount of data, then the research team leaders from the different cultures would take turns analyzing the data related to a single code within the three sets of interview data to produce memos, and finally the full team would discuss and revise the memos. Addenda to initial human subjects protocols were required to provide full access for all team members to all three data sets.

At this stage, the data were still in nine piles in three countries. The interdisciplinary literature was searched for guidance as to how to bring the findings together. This detour into the remarkable epistemological and methodological differences across disciplines in regard to research across cultures was time-consuming, but highly productive. Although the study had been conceptualized as "cross-cultural," the team discovered that a collaborative derived etic approach was closest to the intent of the study to balance between looking across cultures and remaining grounded in the perspective of the participants. The derived etic method (Berry, 1989) is based on an approach in which a focus on the emic perspective, or the subjective understandings held by insiders, is used to provide data for interpreting the findings across cultures.

In the derived etic approach, the etic, or broad and systematic, explanation of the data emerges directly from comparisons of the emic interpretations rather than as an overlaid explanatory structure from a preselected theory. The derived etic approach carefully combines culturally separate understandings of a phenomenon of interest to derive themes in the data that cross the cultures studied. The derived etic method does not assume that the produced description contains universals that transcend all cultures. It does, however, acknowledge that they may exist and that the themes produced may be suggestive of their shape, which differs significantly from the constructivist perspective of most qualitative research.
A delicate methodological balance is thus struck between the etic and emic perspectives that enables a trustworthy examination of one occupation across three cultures, as well as identifying concepts that hold potential for understanding that crosses cultures.

In our first formal attempt to develop a derived etic understanding, two members of the U.S. team and one member of the New Zealand team worked together for 2 weeks in Kentucky in 2003. Their intent was to draft a coding scheme for the comparative analysis based on a review of the full data set. It was not possible for a Thai team member to be in Kentucky, but Thai perspectives were represented to some extent by the New Zealand researcher's understandings from participating in Songkran and spending an extended time discussing the Thai data and findings with her. Thai team members were included through e-mail exchange. This initial part of the process is recognized as imperfect in not being deeply informed by Thai perspectives of the whole data set, illustrating that convening international collaborative teams is a primary challenge of this method. However, as will be shown, later steps involved each culturally situated research team reviewing and interpreting the meaning of their own data from an emic perspective.

The nine initial codes were tradition, change, time, space, food and objects, social, congruence, affect, and occupation/activity. These codes were judged to be centrally interpretive of the processes underpinning the occupations described in the transcripts, and thus aimed to be culturally relevant across the data sets. The codes and definitions of the codes were sent to all members of the research team for feedback. We specifically sought feedback from the Thai team about whether the codes made sense in their context. Although none of the codes proved problematic in themselves, feedback from the Thai research team assisted in their refinement. For example, for the code change, the Thai researchers identified important changes in food preparation that seemed to be minute to the Western researchers, such as using commercially ground rice flour, and this shaped the definition of that code to reach from a larger to a smaller scale of change.

Although it is beyond the scope of this article to describe the results of the study, an example will show how the methods were employed up to this stage. The code "tradition" was used to interpret when the women's occupations followed, preserved, and passed on cultural traditions. In this way, we aimed to look past the culturally disparate practices and consider fundamental meanings. For instance, 
the definition of "tradition" initially included "historical or national influences on tradition" but our focus shifted to "regional influences" when the Thai researchers explained that Songkran observances in their region were markedly different from other parts of Thailand and that the older women of Chiang Mai were specific in maintaining their traditions. For example, the foods and temple activities vary by region and carrying them out as close to tradition as possible resulted in spiritual merit. Such discussions, in turn, sensitized the other two teams to the regional specificity of their own data. Having agreed on initial codes, two researchers (one from New Zealand and one from Kentucky) used Ethnograph software AQ2 to separately and fully code the data of all three countries.

The research collaboration then went through an extended process of refining its derived etic methods to best honor the cultural integrity of the researchers and data, yet produce rigorous comparative descriptions. The initial plan for a lead researcher to produce a memo for the team to discuss via audioconference and written commentary was ineffective and highly demanding for the lead researcher. The first memo, on the code "tradition" was 30 pages single spaced and carefully supported by data excerpts, but the team was not satisfied with its crosscultural interpretations. Illustrative of this difficulty, the attempt at synthesizing Thai traditions began by seeking further explanation of traditional practices: "Is miang a food? Is the food taken to the temple intended for particular individuals?" Although the team had planned to rotate the lead researcher role across the three emic teams, it was determined that this did not keep the interpretations grounded well enough in local understandings of the data.

\section{An Emerging Process}

To make headway with the analyses, all members of the research team met in Chiang Mai for 2 weeks in 2005 immediately following Songkran. At this meeting, a more satisfactory derived etic methodology emerged through trials and in-depth discussion centering on each team's interpretation of their own data for each code. In the final applied design for implementing the derived etic approach, a series of six rigorous steps were implemented for each code:

1. Simultaneous written analyses by researchers working within their separate teams interpreting the coded data from their region and referring back to the original transcripts to ensure accuracy were completed.
2. Each team presented their interpretations to the full collaborative team in writing and in overview table formats.

3. The full collaborative team discussed and pursued personal understandings of the provided analyses, working to ensure language that captured emic meanings and to resist comparative conclusions.

4. The full collaborative team derived, through discussion, primary (derived etic) themes present in the three sets of emic interpretations for a single code, although each idea might have been expressed in different ways in each cultural data set.

5. Each team reorganized its findings within the derived etic themes, bringing in illustrations from the raw data to show how it was expressed (or not) within their regional data.

6. Each team presented its findings within the derived etic themes for discussion by the full collaborative team, with all teams seeking comparative likenesses and differences. Consensus of meaning from each region was not sought.

To illustrate this process, the teams worked within the coded data of their own country to prepare a memo about tradition. To build mutual understanding, the teams described their findings and answered questions. For example, the New Zealand team explained that some older women reject traditional foods because the weather is too hot in December and celebrate their new "traditions" as better suiting their family and forging an identity as New Zealanders. After all memos on tradition were presented and discussed, it became apparent that women's involvement in directing what would happen was part of tradition. This became a theme, and each team considered how it manifested in their data.

Thus, older women in Chiang Mai are recognized as the leaders, planners, directors, and primary preparers of the food to take to the temple. In Kentucky, the older women lead an age-related grouping of female family members in preparing the foods for the Christmas meal according to their different skill levels and the meal is usually in the older woman's home. In New Zealand, the older women coordinate the preparations in the background and many people bring food for the meal, which is often held in a different location each year. Recognizing these variations, we found that women's roles as leaders were affected by the rate of cultural change, with Thai women at one extreme enacting a role that fostered continuity and the New Zealand women participating in and fostering ongoing change through their participation in this family occupation. 
The most appropriate progression for analysis of the different codes was carefully chosen to maximize contrasts and produce insights. As each code was analyzed, transcending themes began to recur. For example, the preservation, reenactment, or invention of regional identity was threaded throughout the data. The extreme difference in data of such different cultures brought into sharp relief a surprising series of unanticipated insights into food-centered occupations.

Analysis of all codes was not completed in Thailand. With the structure of the methods in place, however, the team was able to continue to work separately, with monthly audio conference meetings and exchanges of documents. Late in the analyses of the sequence of codes, the team began to overlap the initiation and completion of code analyses. In 2005, two Thai researchers, one New Zealand researcher, and two U.S. researchers worked in Kentucky for 2 weeks to bring the analysis to a point where publications describing the research process and etic analysis could be considered. At this time, live video conferencing was also initiated and is expected to continue as an effective method of team collaboration as write-up requires further discussion and work with the data. This article provides the first brief written report of a rich set of results, which are planned for topical dissemination to interdisciplinary and disciplinary journals in the near future. The team has developed, over long involvement, effective collaboration and communication across cultures and highly values its work to transcend cultural boundaries within occupational science and therapy.

\section{Conclusions}

The derived etic method of the international study of food preparation occupations of older women in the United States, Thailand, and New Zealand promises potential for occupational therapy and occupational science to bridge the epistemological divide that may exist when researchers in occupational science and therapy draw highly variant methods and philosophical stances from established external disciplines. The current debate in occupational therapy regarding the transferability of the profession's concepts across cultures has been briefly reviewed here. Clearly, questions of cross-cultural description or application being entertained separate from an understanding of their epistemological assumptions results in researchers and theorists who are talking past one another.

The international food preparation study strikes a fine balance between local emic understandings and etic/comparative understandings through a method that is consistently attentive to international collaboration. This approach demonstrates one process through which occupational science and therapy may test and transcend the cultural boundedness of many of their primary theories to push the growth of knowledge rapidly forward.

This study demonstrates methods that can assist occupational scientists and therapists in looking across cultures and transcending epistemological divisions. To develop, test, and refine the knowledge of occupational science and therapy, key phenomena might be fruitfully compared across international cultures, across cultures of different sub-populations within a particular nation, or even across clinical cultures. However the collaborative derived etic method demonstrated here may be used, it promises great potential for informing the profession, transforming its knowledge base, and enhancing the effectiveness of its interventions.

\section{References}

Berry, J. W. (1989). Imposed etics-emics-derived etics: The operationalization of a compelling idea. International Journal of Psychology, 24, 721-735.

Berry, J. W., Poortinga, Y. H., Segall, M. H., \& Dasen, P. R. (2002). Cross-cultural psychology: Research and applications (2nd ed.). New York: Cambridge University Press.

Blanche, E. I., \& Henny-Kohler, E. (2000). Philosophy, science and ideology: A proposed relationship for occupational science and occupational therapy. Occupational Therapy International, 7, 99-110

Bonder, B. R. (2004). Culture emergent in occupation. American Journal of Occupational Therapy, 58, 159-168.

Chan, C. L., Ray, S., \& Trudeau, S. (2001). The development and reliability of the Cantonese version of the Allen Cognitive Level Screen. Occupational Therapy International, 8, 287-300.

Corless, I. B., Nicholas, P. K., \& Nokes, K. M. (2001). Issues in cross-cultural quality-of-life research. Journal of Nursing Scholarship, 33, 15-20.

Divale, W., \& Seda, A. (2001). Modernization as changes in cultural complexity: New cross-cultural measurements. CrossCultural Research, 35, 127-153.

Ember, C. R., \& Ember, M. (1998). Cross-cultural research. In H. R. Bernard (Ed.), Handbook of methods in cultural anthropology (pp. 647-687). Walnut Creek, CA: AltaMira Press.

Fidler, G. S. (1996). Life-style performance: From profile to conceptual model. American Journal of Occupational Therapy, 50, 139-147.

Fitzgerald, M. H. (2004). A dialogue on occupational therapy, culture, and families. American Journal of Occupational Therapy, $58,489-498$.

Gelfand, M. J., Raver, J. L., \& Ehrhart, K. H. (2002). Methodological issues in cross-cultural organizational research. In S. G. Rogelberg (Ed.), Handbook of research methods in industrial and organizational psychology (pp. 216-246). Malden, MA: Blackwell. 
Gibbs, M. (2001). Toward a strategy for undertaking cross-cultural collaborative research. Society and Natural Resources, 14, 673-687.

Haglund, L., \& Kjellberg, A. (1999). A critical analysis of the Model of Human Occupation. Canadian Journal of Occupational Therapy, 66, 102-108.

Hines, A. M. (1993). Linking qualitative and quantitative methods in cross-cultural survey research: Techniques from cognitive science. American Journal of Community Psychology, 21, 729-746.

Hocking, C. (1999, September). The cultural nature of occupation: A Model of Human Occupation perspective. Paper presented at the Second Asia-Pacific Occupational Therapy Congress, Taipei, People's Republic of China.

Hocking, C., \& Whiteford, G. (1995). Viewpoint: Multiculturalism in occupational therapy: A time for reflection on core values. Australian Occupational Therapy Journal, 42, 172-174.

Hocking, C., \& Whiteford, G. (1997). What are the criteria for development of occupational therapy theory? A response to Fidler's life style performance model. American Journal of Occupational Therapy, 51, 154- 157.

Hocking, C., Wright-St. Clair, V., \& Bunrayong, W. (2002). The meaning of cooking and recipe work for older Thai and New Zealand women. Journal of Occupational Science, 9, 117-127.

Hwang, J., Nochajski, S. M., Linn, R. T., \& Wu, Y. B. (2004). The development of the School Function Assessment - Chinese version for cross-cultural use in Taiwan. Occupational Therapy International, 11, 26-39.

Iwama, M. (2003). Toward culturally relevant epistemologies in occupational therapy. American Journal of Occupational Therapy, $57,582-588$.

Iwama, M. (2005). The Kawa (River) model: Nature, life flow, and the power of culturally occupational therapy. In F. Kronenberg, S. S. Algado, \& N. Pollard (Eds.), Occupational therapy without borders: Learning from the spirit of survivors (pp. 213-227). Edinburgh: Elsevier Churchill Livingstone.

Kral, M. J., Burkhardt, K. J., \& Kidd, S. (2002). The new research agenda for a cultural psychology. Canadian Psychology, 43, 154-162.

Levy, L. (1962). Israel. Proceedings of the Third International Congress of the World Federation of Occupational Therapists, Philadelphia, 28-33.AQ3

Lyons, E., \& Chryssochoou, X. (2000). Cross-cultural research methods. In G. M. Breakwell, S. Hammond, \& C. Fife-Schaw (Eds.), Research methods in psychology (2nd ed., pp. 134-146). Thousand Oaks, CA: SAGE Publications.

McArthur, L. H., Anguiano, R. P. V., \& Nocetti, D. (2001). Maintenance and change in the diet of Hispanic immigrants in Eastern North Carolina. Family and Consumer Sciences Research Journal, 29, 309-335.

McGarrigle, J., \& Nelson, A. (2006). Evaluating a school skills programme for Australian Indigenous children: A pilot study. Occupational Therapy International, 13, 1-20.

Michaud, P., Blum, R. W., \& Slap, G. B. (2001). Cross-cultural surveys of adolescent health and behavior: Progress and problems. Social Science and Medicine, 53, 1237-1246.

Neuman, A. (2006). Patterns of response to sensory stimuli encountered in daily activities: A comparison between 3-10year-old Israeli and American children without disabilities. Occupational Therapy International, 13, 79-99.
Neuman, A., Greenberg, D. F., Labovitz, D. R., \& Suzuki, L. A. (2004). Cross-cultural adaptation of the Sensory Profile: Establishing linguistic equivalency of the Hebrew version. Occupational Therapy International, 11, 112-130.

Odawara, E. (2005). Cultural competency in occupational therapy: Beyond a cross-cultural view of practice. American Journal of Occupational Therapy, 59, 325-334.

Oza, R. K. (1962). India. Proceedings of the Third International Congress of the World Federation of Occupational Therapists, Philadelphia, 42-44.AQ3

Pan, A., Chern, J., Chung, L., \& Lai, J. (2001). Inter-rater and test-retest reliability of the Taiwanese Rehabilitation Function Scale. Occupational Therapy International, 8, 168-183.

Parry, K. K. (1984). Concepts from medical anthropology for clinicians. Physical Therapy, 6, 929-933.

Pike, K. L. (1967). Language in relation to a unified theory of the structure of human language. The Hague, Netherlands: Mouton.

Ratima, M., \& Ratima, M. (2005). Practice in an indigenous context. In G. Whiteford \& V. Wright-St. Clair (Eds.), Occupation and practice in context (pp. 230-241). Sydney: Elsevier Churchill Livingstone.

Rattakorn, P., Vittayakorn, S., Bunrayong, W., Hocking, C., \& Wright-St. Clair, V. (2003). Cooking food for Songkran: Its meaning for the elderly women of Chiangmai [article in Thai]. Journal of Occupational Therapists Association of Thailand, 8, 32-40.

Robertson, F. M. (1960). Evaluation of skills in a double hand amputee. Occupational Therapy, 23, 19-20.

Shordike, A., \& Pierce, D. (2005). Cooking up Christmas in Kentucky: Occupation and tradition in the stream of time. Journal of Occupational Science, 12, 140-148.

Skevington, S. M. (2002). Advancing cross-cultural research on quality of life: Observations drawn from the WHOQOL development. Quality of Life Research, 11, 135-144.

Teresi, J. A., \& Holmes, D. (2001). Some methodological guidelines for cross-cultural comparisons. Journal of Mental Health and Aging, 7, 13-19.

van de Vijver, F. J. R. (2001). The evolution of cross-cultural research methods. In D. Matsumoto (Ed.), The handbook of culture and psychology (pp. 77-97). Oxford, England: Oxford University Press.

van de Vijver, F. J. R., \& Poortinga, Y. H. (2002). On the study of culture in developmental science. Human Development, 45, 246-256.

Watson, R., \& Swartz, L. (Eds.). (2004). Transformation through occupation. London: Whurr.

Whiteford, G., Townsend, E., \& Hocking, C. (2000). Reflections on a renaissance of occupation. Canadian Journal of Occupational Therapy, 67, 61-69.

Whiteford, G. E., \& Wilcock, A. A. (2000). Cultural relativism: Occupation and independence reconsidered. Canadian Journal of Occupational Therapy, 67, 324-336.

Wright-St. Clair, V., Bunrayong, W., Vittayakorn, S., Rattakorn, P., \& Hocking, C. (2004). Offerings: Food traditions of older Thai women at Songkran. Journal of Occupational Science, 11, 115-124.

Yang, S., Shek, M. P., Tsunaka, M., Lim, H. B. (2006). Cultural influences on occupational therapy practice in Singapore: A pilot study. Occupational Therapy International, 13, 176-192. 


\section{AUTHOR QUERIES}

General Please provide degrees for all authors.

AQ1 Please provide three key words for your article.

AQ2 Provide the manufacturer and its location.

AQ3 Are the Levy and Oza references chapters or articles that have been published in proceedings (either in a book or a journal)? If so, please indicate where the articles have been published. 